\title{
Remarkable recovery of a steroid-responsive recurrent polyneuropathy
}

\author{
DARRYL C. DeVIVO AND W. KING ENGEL \\ From the Medical Neurology Branch, National Institute of Neurological Diseases and Stroke, Nationat \\ Institutes of Health, Public Health Service, U.S. Department of Health, Education, and Welfare, Bethesda. \\ Maryland, U.S.A.
}

Idiopathic recurrent polyneuropathy is one of several distinct syndromes involving the peripheral nervous system which share similar microscopic alterations of the interesting Schwann cell-myelin sheath of the axon collectively referred to as hypertrophic neuropathies (Austin, 1956; Byers and Taft, 1957; Thomas and Lascelles, 1967). In all six patients with hypertrophic neuropathy studied by Thomas and Lascelles (1967), extensive segmental demyelination was present. Moreover, this paranodal loss of myelin was seen in certain areas in the absence of any other pathological alteration, suggesting to these investigators that segmental demyelination was the initial morphological alteration in these diseases. Presumably, if this process of demyelination and subsequent remyelination continues, other characteristic alterations ensue, including shortening of the internodal lengths, as seen on longitudinal sections, and concentric cellular proliferation around individual axons with variable accumulation of 'connective tissue' in the endoneurial spaces as seen on crosssection. These reactive changes to chronic injury have been shown to be manifestations of Schwann cell proliferation (Thomas and Lascelles, 1967; Garcin, Lapresle, Fardeau, and deRecondo, 1966; Webster, Schröder, Asbury, and Adams, 1967). Although the pathological features are similar, the stimulus to or mechanism of cellular proliferation in these various conditions may be quite different. Recently Arnason, Asbury, Aström, and Adams (1968) have suggested experimental allergic neuritis as a possible model for acute idiopathic polyneuritis. In both these conditions segmental demyelination is a characteristic finding.

In certain of these hypertrophic neuropathies, variably referred to as recurrent polyneuropathy (Austin, 1958), recurrent hypertrophic polyneuritis (Nattrass, 1921-22), and chronic Guillain-Barré syndrome (Hinman and Magee, 1967), treatment with glucocorticoids has been followed by variable degrees of improvement in the patient's condition (Austin, 1958; Hinman and Magee, 1967). However; since Austin's detailed observations in 1958 on the steroid responsiveness of certain recurrent hyper? trophic neuropathies (Austin, 1958), little more has been added to the literature on this aspect of the subject.

This report describes a 12-year-old girl wwo suffered from a chronic relapsing polyneuropatin which proved to be steroid responsive. After $\$ 6$ months of virtual quadriplegia and 30 mon sis $^{-}$ from onset, she recovered dramatically on prot longed treatment to the point of independent? ambulation and has continued in remission on ofm alternate day programme of steroid treatment.

\section{CASE REPORT}

An 11-year-old white girl (NIH 07-66-59) was admittedo to the Medical Neurology Branch for evaluation of as chronic relapsing peripheral neuropathy of three years? duration. She had been well until the age of 8 . Gradually, thereafter, during the autumn of 1964 , bilateral weakness of ankle dorsiflexion evolved over a three month period, manifested initially by frequent stumbling and steppageo gait. Later, weakness of hands and wrist extensors appeared. In November 1964, neurological examination in another hospital confirmed a generalized distalo. weakness of arms and legs with areflexia and slighe diminution in response to pin prick over the dista extremities. The remainder of the examination was: normal. Lumbar puncture results included an opening pressure of $200 \mathrm{~mm} \mathrm{H}_{2} \mathrm{O}$, protein $134 \mathrm{mg}$ and glucose $62 \mathrm{mg} / 100 \mathrm{ml}$., and a cell count of three erythrocytes and four mononuclear cells/c.mm. A diagnosis of Guillain-3 Barré syndrome was advanced.

During the next 14 months, her condition worsened? only slightly, without any periods of improvement. Ino late December 1965, a sudden worsening of her disease resulted in onset over a 48 hour period of virtual quadri- $N$ plegia with mild dysphagia and slight dyspnoea necessitating hospitalization. Dexamethasone therapy totalling $20 \mathrm{mg}$ over the subsequent month coincided with gradual $\omega$ 
regression of weakness. The remission continued for three months after discontinuation of the steroid. Spinal fluid proteins of $244 \mathrm{mg}$ and $200 \mathrm{mg} / 100 \mathrm{ml}$. were recorded during this four month period.

In late May 1966, the patient relapsed over a period of six weeks again to a quadriplegic state. In July 1966, dexamethasone therapy was resumed with a total dosage of $165 \mathrm{mg}$ given over six weeks. Her condition again remitted slowly, coincident with steroid treatmentbut after a three to four week lag period-and continued for $2 \frac{1}{2}$ months after discontinuation of the steroid. Admission to a second hospital at the beginning of remission in late August 1966 involved an extensive re-evaluation. Neurological findings included marked weakness of distal and proximal muscles of the arms and legs and generalized areflexia. Cross-sections of the sural nerve biopsy revealed a decrease in the number of myelinated fibres, the largest measuring $9 \mu$ in diameter. Details of these findings are reported by Dyck, Gutrecht, Bastron, Karnes, and Dale (1968) as case 42-66. Segmental demyelination was shown on longitudinal sections.
Surrounding the individual remaining myelinated fibres, proliferating Schwann cells were seen in the characteristic 'onion bulb' formation. Electromyography revealed a pattern of denervation, including fibrillations and a mixed interference pattern containing polyphasic potentials of increased amplitude.

Gradual recovery continued until November 1966, when the patient could take a few steps with a walking aid, followed by slow exacerbation until January 1967, at which point she was bedridden and totally dependent on her parents for care. Other than facial and neck movements, she was quadriplegic in bed and remained so through her admission to the National Institutes of Health in late November 1967. Bladder and bowel function have always been normal.

When admitted the patient was a pleasant, obese young girl with prominent cushingoid features (see Fig. 1a). Pupils were normally reactive and extraocular movements were full. Optic disc margins were indistinct bilaterally with some fullness of the nerve head. Spontaneous venous pulsations were present. Visual acuity

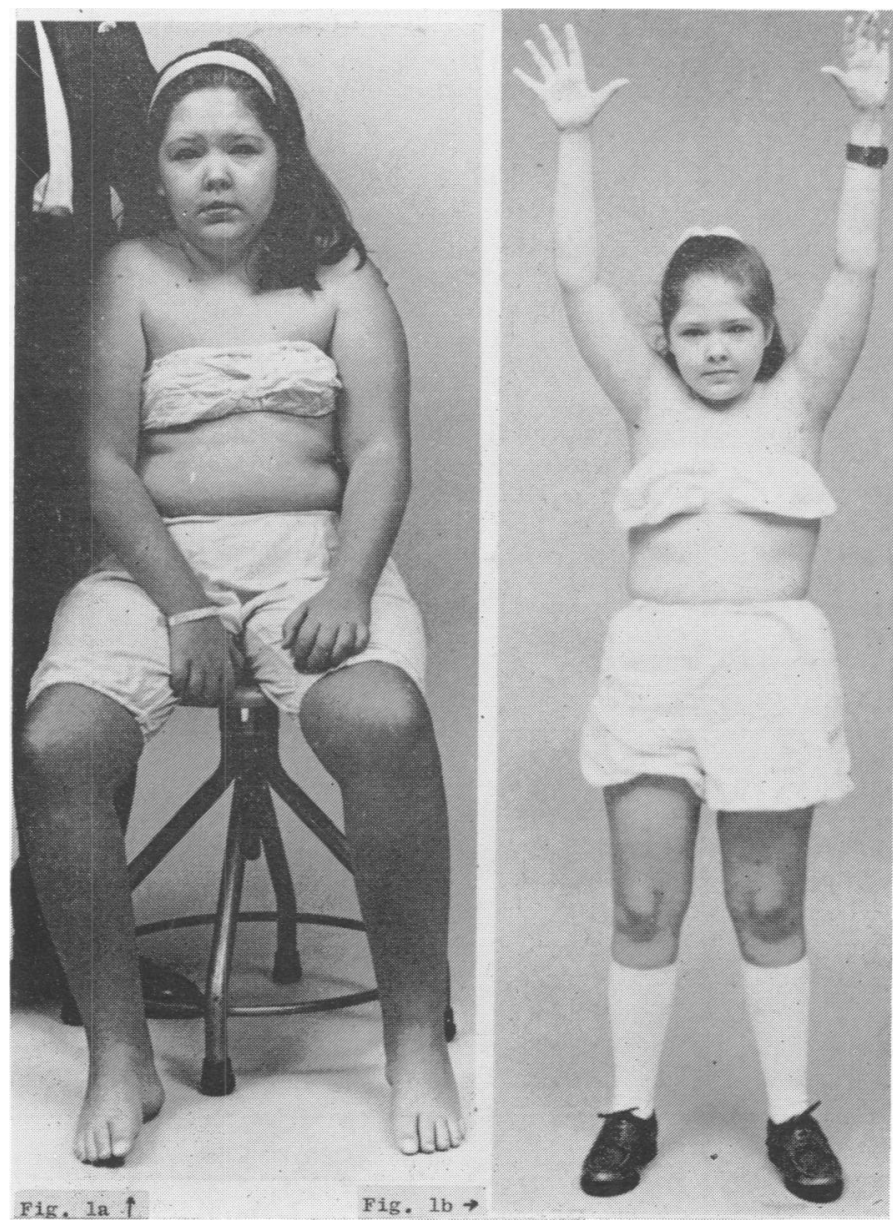

FIG. 1. (a) Admission photograph in November 1967. The patient required assistance by her father to remain in the sitting position. Note the cushingoid appearance and the absence of contractures. (b) April 1969, 17 months after reinstitution of prednisone and five months after conversion to alternate day programme. Patient is fully independent and ambulatory at this time. 
was normal bilaterally. There was profound weakness of distal and proximal muscles in arms and legs with resulting inability to raise her limbs off the bed or move any major joint through a range of motion with gravity eliminated. Only a flicker of flexor movement was appreciated in the fingers or toes. Deep tendon reflexes were absent. Careful sensory examination failed to document any deficit in pain, temperature, light touch, position, or vibration. Superficial abdominal reflexes were present; plantar responses were flexor. On palpation ulnar and peroneal nerves were quite firm though not clearly enlarged. Remainder of the findings were unremarkable. Vital capacity on admission ranged from 1,000 to $1,600 \mathrm{ml}$., falling to $580 \mathrm{ml}$. one week later.

The patient remained hospitalized continuously for 13 months.

LABORATORY DATA Blood and urine studies remained consistently normal or negative on repeat evaluation. Normal admission studies included haemoglobin, haematocrit, platelet count, white blood cell count and differential, erythrocyte sedimentation rate, serological test for syphilis, and lupus erythematosus preparations. Normal blood chemical findings included urea nitrogen, fasting sugar, cholesterol, phosphorus, total protein and paper electrophoretic pattern, uric acid, total bilirubin, creatinine, thyroxine, sodium, potassium, chloride, carbon dioxide, calcium, magnesium, alkaline phosphatase, serum glutamic oxalo-acetic transaminase, serum glutamic pyruvate transaminase, lactic dehydrogenase, and serum creatine phosphokinase. The blood sugar two hours after oral loading $(1.75 \mathrm{~g}$ glucose $/ \mathrm{kg}$ body weight) was $144 \mathrm{mg} / 100 \mathrm{ml}$.

Normal $24 \mathrm{hr}$ urine analyses included 17-hydroxycorticosteroids $6.4 \mathrm{mg} / 24 \mathrm{hr}, 17$-ketosteroids $5.7 \mathrm{mg} / 24 \mathrm{hr}$, $a$-amino nitrogen $70 \mathrm{mg} / 24 \mathrm{hr}$, lead $2 \mu \mathrm{g} / 100 \mathrm{ml}$., mercury $1 \mu \mathrm{g} / 100 \mathrm{ml}$., arsenic non-detectable, coproporphyrins negative, uroporphyrins negative, porphobilinogen negative.

Seventy-two hour stool collections while on a $100 \mathrm{~g}$ fat diet on two occasions revealed $3.3 \mathrm{~g}$ and $2.8 \mathrm{~g}$ faecal fat $/ 24 \mathrm{hr}$ (normal less than $5 \mathrm{~g} / 24 \mathrm{hr}$ ).
Results of lumbar puncture on each occasion were $Z$ abnormal and are summarized in the Table.

ELECTROMYOGRAPHY AND NERVE CONDUCTION STUDIES Sampling of various muscles in the extremities showed a⿳亠二口犬 marked loss of motor unit potentials with a patterno reduced to single oscillations on maximal volitional effort? The remaining motor unit potentials were normal tof slightly increased in amplitude and duration and demon strated mild polyphasia. Fibrillations were also present. in the majority of proximal and distal muscles tested In the initial examination, motor conduction times couldes not be calculated because potentials could be evokedo from only one point on the median and ulnar nerveso and none was obtained from the peroneal and tibia/ nerves. The initial distal latency of the left median nerve when stimulated at the wrist and recorded over the thenar eminence was $19 \mathrm{msec} / 55 \mathrm{~mm}$, but difficultiesen associated with recording the small evoked potential$(50 \mu \mathrm{V})$ may have made this measurement inaccurate: Subsequent studies of motor conduction velocity and $\vec{\omega}$ distal latency throughout hospitalization are describedo under 'Results of Treatment'. Using ring electrodes, noכ sensory responses could be elicited over the median or ulnar nerves with stimulations either at the wrist or thew elbow and attempted recording of antidromic potentials. in the fingers.

MUSCLE BIOPSY Biopsy of the right biceps muscle wass performed, with some tissue being fixed, embedded $\overrightarrow{\mathrm{p}} \mathrm{n}-$ paraffin and stained by conventional methods and anotherT portion fresh frozen and stained by enzyme histochemicalo methods (Engel and Brooke, 1966). In both instan\&s the muscle was abnormal; muscle fibres varied in ameter from 8 to $55 \mu$. The majority of these fib remained round or somewhat angular with lesser num- $\theta$ bers being truly angular. Interspersed among the atro- 0 phied fibres were several 'hypertrophied' fibres measuring 45 to $55 \mu$ in diameter. Histochemistry demonstrated two distinct fibre types as defined by their respective staining properties (Engel and Brooke, 1966). The ma-음 jority of these fibres retained their enzymatic identityo

TABLE

CEREBROSPINAL FLUID RESULTS

\begin{tabular}{|c|c|c|c|c|c|c|c|}
\hline Date & $\begin{array}{c}\text { Opening } \\
\text { pressure } \\
\left(\mathrm{mm} \mathrm{H} \mathrm{H}_{2} \mathrm{O}\right)\end{array}$ & Appearance & Cells $/ \mathrm{mm}^{8}$ & $\begin{array}{l}\text { Protein }(\mathrm{mgl} \\
100 \mathrm{ml} .)\end{array}$ & $\begin{array}{l}\text { Sugar ( } \mathrm{mg} / \\
100 \mathrm{ml} .)\end{array}$ & $\begin{array}{l}\text { Colloidal } \\
\text { gold }\end{array}$ & Serology \\
\hline 27 November 1967 & 370 & $\begin{array}{l}\text { Colourless, } \\
\text { clear }\end{array}$ & $\begin{array}{l}343 \text { RBC, } \\
3 \text { lymphocytes }\end{array}$ & 186 & 64 & 1122221000 & Non-reactive \\
\hline 18 December 1967 & 240 & $\begin{array}{l}\text { Colourless, } \\
\text { clear }\end{array}$ & $\begin{array}{l}1 \text { PMN, } \\
6 \text { lymphocytes }\end{array}$ & 174 & 79 & 1112222100 & - \\
\hline 4 January 1968 & 210 & $\begin{array}{l}\text { Slight } \\
\text { straw } \\
\text { colour, } \\
\text { clear }\end{array}$ & $\begin{array}{l}3 \text { RBC, } \\
1 \text { lymphocyte }\end{array}$ & $237^{1}$ & 52 & 1112222110 & Non-reactive \\
\hline 18 January 1968 & 220 & $\begin{array}{l}\text { Straw } \\
\text { colour, } \\
\text { clear }\end{array}$ & 30 RBC & 285 & 62 & 1111222211 & - \\
\hline
\end{tabular}

${ }^{1}$ CSF protein electrophoresis: albumin $65 \%, a_{1}$ globulin $4 \%, a_{2}$ globulin $9 \%, \beta$ globulin $11 \%, \gamma$ globulin $11 \%$. Radial immunodiffusion plates (Hyland Laboratories): IgG $23.1 \mathrm{mg} \%$, IgA $0.25 \mathrm{mg} \%$, IgM 0.008 mg \%. No low molecular weight IgM was detected using $4 \%$ polyacrylamide gel diffusion. 
as either type I or type II (see Fig. 3). Scattered throughout the section, a few small dark, angulated fibres were stained abnormally dark with the reduced diphosphopyridine nucleotide tetrazolium reductase reaction. A small intramuscular nerve twig was fibrosed, showing a prominent laminated 'swirling' pattern on cross section (Fig. 3d).

TREATMENT The patient's clinical course and treatment are summarized in Fig. 2. To follow her condition, detailed clinical evaluations were repeated twice weekly, vital capacities were recorded daily, and electrical studies of nerve and muscle were repeated monthly. A daily programme of physical therapy was initiated, including passive and active range of motion exercises and later tilt-table exercises. Oral prednisone therapy was begun on 29 November 1967, at a dose of $15 \mathrm{mg}$ t.i.d. Potassium chloride syrup (60 m-equiv daily) and antacids were also given in conjunction with the glucocorticoid. Prednisone dosage was gradually reduced, starting 10 January 1968 , to reach the level of $7.5 \mathrm{mg}$ b.i.d. on 15 April 1968. This dosage was continued through 30 November 1968 and then gradually converted over the next month to an alternate day regimen $(40 \mathrm{mg}$ prednisone every other day at 8 a.m.) Also on 18 December 1967 and again on 4 January 1968, $80 \mathrm{mg}$ methylprednisolone acetate was administered intrathecally. Other medications included chloroquine $125 \mathrm{mg}$ b.i.d. from 25 January 1968 through until 27 August 1968, during which time the patient received a total dosage of $55 \mathrm{~g}$. Supplemental oral vitamins were begun on 18 April 1968 (folic acid $10 \mathrm{mg}$ daily and one hexavitamin capsule daily) and on 10 September 1968 (pyridoxine hydrochloride $25 \mathrm{mg}$ daily).

The patient's diet was rigidly controlled at a hypocaloric level of 800 to 1,000 cals. and $70 \mathrm{~g}$ protein with no added salt. During hospitalization she lost $7.7 \mathrm{~kg}$, still remaining moderately overweight $(51.8 \mathrm{~kg})$ at the time of discharge.
RESULTS OF TREATMENT Within 48 hours of beginning prednisone and potassium chloride therapy, a very small functional improvement was observed. The patient regained the ability to roll 5 to $10^{\circ}$ laterally in either direction while supine. There was no appreciable recovery of motor function beyond this point for the next $3 \frac{1}{2}$ months. However, the daily vital capacity measurements reflected subtle, continual improvement from week to week. Three and a half months after prednisone was started and $1 \frac{1}{2}$ months after chloroquine was added to the regimen, the patient clearly began recovering strength, first in her arms and hands, later in her feet and toes. In the fifth month of therapy she was able to feed herself for the first time in 16 months. Vital capacity measurements continued to improve, reaching $100 \%$ of predicted normal for age by the eleventh month of treatment. Her functional recovery of summated motor power from late March (fourth month) through December (thirteenth month) was virtually linear, as depicted in Fig. 2.

At time of discharge the patient was fully independent in daily activities; she was able to rise from supine to sitting and sitting to standing without assistance and walk alone 25 to $30 \mathrm{ft}$. $(7 \cdot 6 \mathrm{~m}$ to $9 \cdot 1 \mathrm{~m})$ before tiring. With crutches, she would walk several hundred feet and one flight of stairs. Her hand movements showed remarkable return of function, with no contractures or deformities. Finger dexterity at time of discharge was excellent; she was able to write and sew with facility. Mild cushingoid features remained. She had clear, articulate speech and normal cranial nerve function. Sensory examination remained normal. Detailed cerebellar testing of appendicular functions failed to demonstrate any abnormality. However, stance was mildly broad based, and gait had an ataxic quality with marked unsteadiness and rapid fatigue appearing when crutches were removed. Strength was considered normal in the neck and arms and almost normal in the proximal groups of the legs. Distally, tibial and peroneal muscle groups remained moderately weak with slight foot drop bilaterally. She was able to

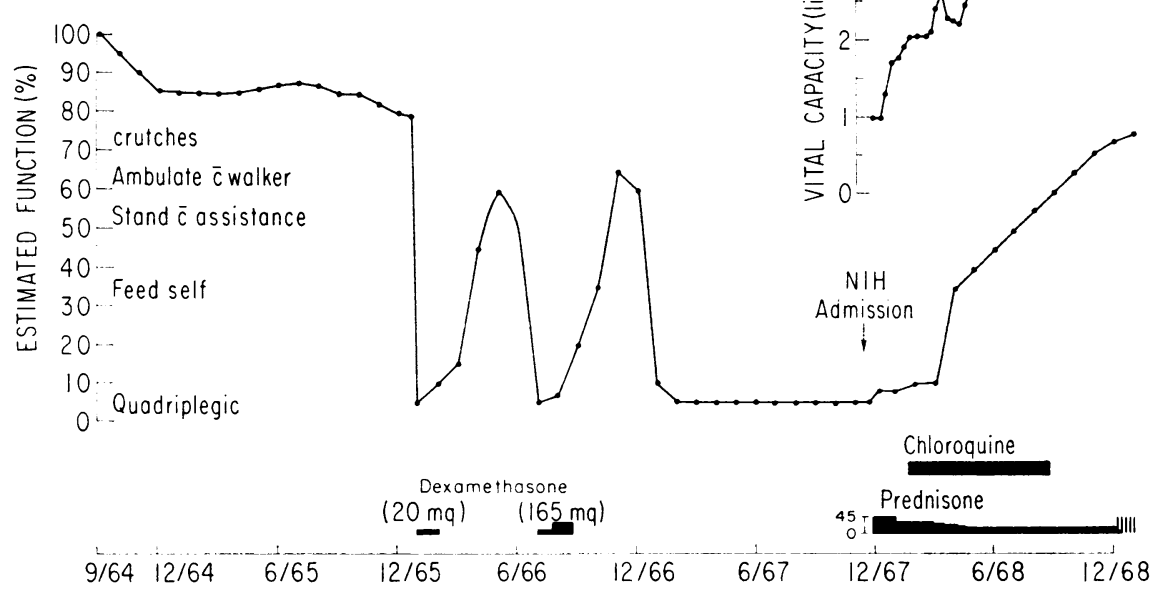

FIG. 2. Summary of the clinical course from onset October 1964 through discharge from NIH December 1968. Estimated function is an integration of summated motor power and ability to perform certain tasks. 


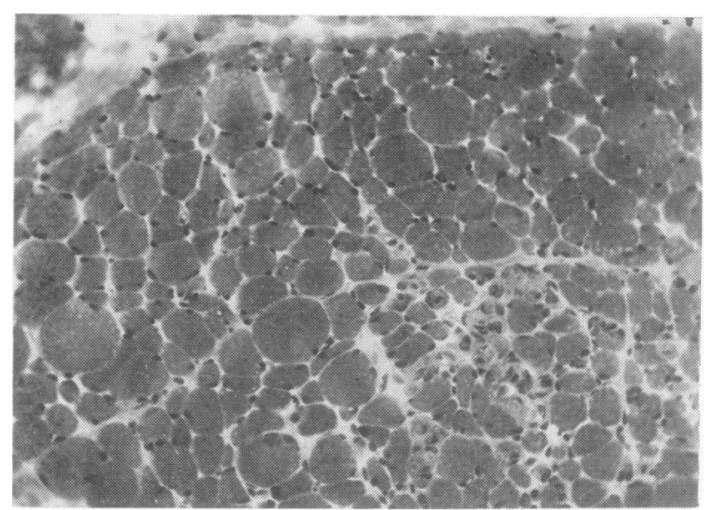

(a)

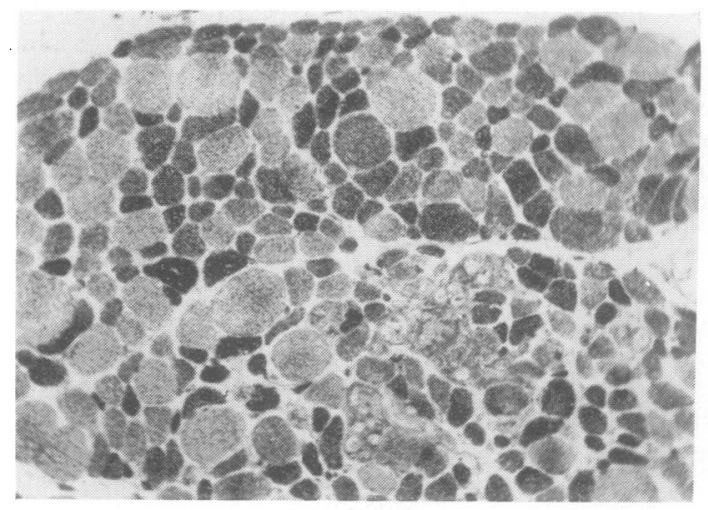

(c)

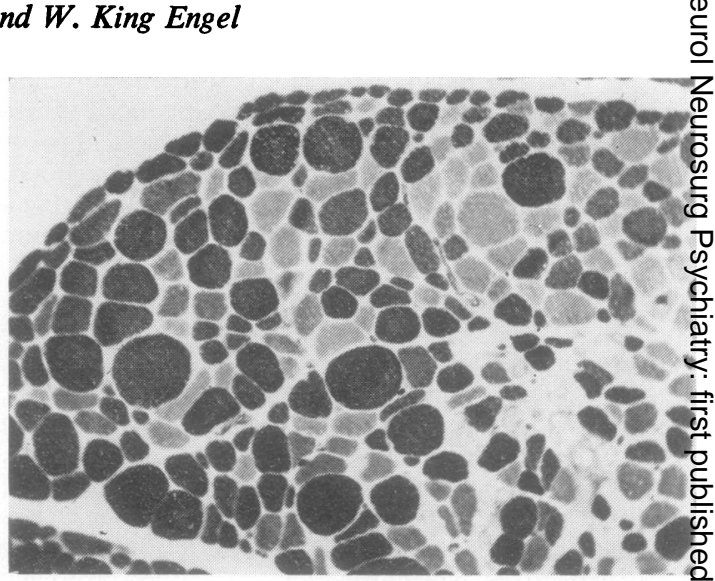

(b)

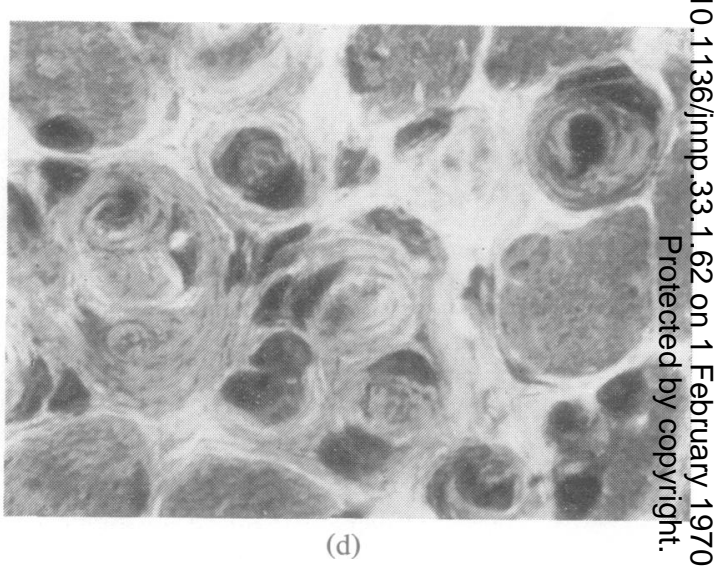

FIG. 3. Muscle biopsy showing serial sections stained by enzyme histochemical methods; (a) modified Gomori trichrom§ $(\times 120)$ showing the marked variation in fibre size with the majority remaining round or somewhat angular: (b) myof brillar ATPase reaction $(\times 120)$ showing darkly stained type II muscle fibre and lightly stained type I muscle fibres Note the marked variation in fibre diameters, with scattered large fibres (55 $\mu$ ) among smaller atrophied fibres: (c) diphos: phopyridine nucleotide tetrazolium reductase reaction $(\times 120)$ with darkly stained type I muscle fibres and lightly stainea type II fibres. A few smaller angular fibres stain intensely for oxidative enzyme activity characteristic of denervatea fibres: (d) the intramuscular nerve fibres toward the centre of the field in ' $a$ ' at higher magnification $(\times 760)$ show mye $\overrightarrow{\overrightarrow{0}}$ linated fibres enveloped in a laminated, swirling overgrowth of investing nerve sheath frequently referred to as 'onion bulb' formation.

stand erect unassisted with feet together and eyes closed. Deep tendon reflexes remained absent. Her medications included prednisone $40 \mathrm{mg}$ every other day, folic acid $10 \mathrm{mg}$ daily, pyridoxine $\mathrm{HCl} 25 \mathrm{mg}$ daily, and potassium chloride syrup $40 \mathrm{~m}$-equiv daily. The initially unrecordable motor conduction velocities became obtainable two months after admission and from that time to five months after discharge remained slowed at 20 to 28 $\mathrm{m} / \mathrm{sec}$ in the ulnar and median nerves. After discharge, conduction time in the peroneal nerve was still very slow at $9 \mathrm{~m} / \mathrm{sec}$. Distal latencies of the median nerve at the wrist remained prolonged at from 5 to $8 \mathrm{msec} / 50 \mathrm{~mm}$ throughout hospitalization. At no time could sensory nerve responses be recorded.
Since discharge the patient has continued on ars alternate day steroid programme for five months and has remained in remission, continuing gradually to recover additional motor function (see Fig. 1b).

\section{DISCUSSION}

The major purpose of this report is to emphasize (1) the remarkable recovery of a person with idio pathic recurrent polyneuropathy after reinstitution of glucocorticoid therapy after she had lain quadrin plegic for over 13 months, and (2) the long lag period 


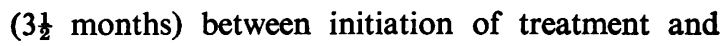
appearance of clear-cut clinical improvement.

This patient illustrates the typical features of an idiopathic chronic relapsing hypertrophic polyneuropathy. Extending over four years, there were three well-documented clinical exacerbations followed by remissions. At no time since onset has the patient been completely well. However, despite periods of total inactivity extending up to 16 months, joint deformities did not develop and contractures were limited to slight heel cord shortening. Such lack of prominent contractures even after a long period of weakness is characteristic of this type of illness. On every occasion, CSF protein values were elevated; the protein electrophoresis and immunoglobulin studies on one sample (see the Table) were qualitatively normal, with quantitative increases in all fractions being the major feature. These observations coincide precisely with the immunochemical studies on CSF proteins in the Guillain-Barré syndrome reported by Ravn and Jensen (1965) and by Osuntokun, Prineas, and Field (1966).

Pathologically, sural nerve biopsy findings showed segmental demyelination, characteristic 'onion bulb whorling' of proliferating Schwann cells and an increase in endoneurial connective tissue (Dyck, Gutrecht, Bastron, Karnes, and Dale, 1968); an intramuscular nerve twig showed increased endoneurial connective tissue and laminated swirls around myelinated fibres (Fig. 3d).

Electrophysiologically, a pattern of denervation was seen on EMG; motor and sensory nerve conduction velocities were profoundly slowed, with prolonged distal latencies. Although improved, the conduction velocities remained quite slow even after remarkable clinical recovery had occurred.

The response to glucocorticoid therapy, although ultimately rewarding, was preceded by a latency period of $3 \frac{1}{2}$ months, during which interval there was only very minimal clinical evidence suggesting recovery. The patient's first exacerbation (Fig. 2) had evolved abruptly over 48 hours after an indolent course of several months; treatment with dexamethasone in low doses (total dose of $20 \mathrm{mg}$ over 30 days) was rather promptly beneficial. The second exacerbation had evolved more slowly; treatment with dexamethasone in much higher doses (total dose of $165 \mathrm{mg}$ over six weeks) was followed by a latency period of three to four weeks before clinical remission became apparent. With the third exacerbation, the patient remained quadriplegic for over 13 months before prednisone treatment was begun. Although there was minimal evidence of benefit documented by weekly improvements in vital capacity measurements (Fig. 2) and subtle changes in detailed manual muscle testing, a latency period of
$3 \frac{1}{2}$ months elapsed before functional recovery could be clearly demonstrated. To generalize from this one patient, and with the assumption that the prolonged administration of oral glucocorticoids was the beneficial factor, the clinical course suggests that the latency period extending from institution of glucocorticoid therapy to the onset of clinically apparent recovery roughly correlates with the total duration of the illness and the length of the preceding exacerbation. In patients with a long exacerbation and/or total course, therapeutic efforts should be continued for at least several months before abandoning hope of recovery. In order to minimize the side effects of glucocorticoids, we include in the treatment programme generous use of antacids, potassium supplementation and a high protein isocaloric diet low in salt and carbohydrate content. Early institution of a vigorous physical therapy programme is considered to aid in off-setting some of the debilitating effects of prolonged inactivity and chronic steroid treatment, and prepare the patient for the postural changes and demands of weight bearing attendant on recovery. An active assisted range of motion exercises and tilt-table manoeuvres were particularly beneficial in this case.

The possible therapeutic benefits of intrathecal glucocorticoids, chloroquine, and supplemental vitamins given to this patient remain unclear. Because of the patient's precarious state, the high CSF protein values, and the known involvement of spinal roots as well as peripheral nerves in this type of disease (Haymaker and Kernohan, 1949), it was elected to administer glucocorticoids by the intrathecal route as well. There is no clear evidence, however, that this route of administration hastened the rate of recovery.

Also to be emphasized is the patient's continuing remission while on alternate day steroid treatment and a simultaneous regression of her cushingoid features. In this case, and in other patients with inflammatory myopathy (DeVivo and Engel, 1969), we have been impressed with this programme in significantly minimizing the serious side-effects of glucocorticoids, while simultaneously maintaining the underlying disease in satisfactory control. Because of the fluctuating nature of the present patient's neuropathy, more time must elapse before one can be confident of the effectiveness of an alternate day regimen in controlling this disease. However, the paucity of side-effects and the proven effectiveness of glucocorticoids in controlling other diseases considered to be immunologically mediated, together with our experience in this case, are encouraging and prompt us to recommend consideration of the alternate day glucocorticoid programme as treatment for idiopathic recurrent 
neuropathy until more specific therapy becomes available.

The basic mechanism of disease and the mode of action of the therapeutic agents in effecting remissions remains to be elucidated. Several years ago, Waksman and Adams (1955) noted the pathological similarity between experimental allergic neuritis (EAN) and idiopathic polyneuritis occurring in humans. More recently Arnason et al. (1968) have suggested EAN as a laboratory model for the human condition, while re-emphasizing the pathological similarities in the two diseases. Studying human necropsy material, they demonstrated lymphocytic infiltrations widely scattered in both dorsal and ventral roots and throughout peripheral nerves even to the terminal twigs. They stated that segmental demyelination corresponded with the areas of cellular infiltration. In another study on EAN, Asbury and Arnason (1968) demonstrated by radioautographic methods two distinct waves of cellular proliferation occurring, the initial wave being in the invading lymphocytes and the second wave occurring later in the endogenous cell population within peripheral nerves, primarily Schwann cells. The second proliferative wave was seen to persist long after all evidence of the inflammatory infiltrate had disappeared.

Yet there is a major difference between experimental allergic neuritis and clinical relapsing polyneuropathy - the former is always an acute monophasic condition while the latter is polyphasic with a number of exacerbations and remissions. (The same distinction exists between experimental allergic encephalomyelitis and multiple sclerosis.) If a parallel is to be drawn between experimental allergic neuritis and the relapsing polyneuropathy of the present patient, a mechanism for repeated acute insults to peripheral nerve must be postulated, and alteration of this mechanism could then account for clinical improvement.

Therefore, it seems reasonable to suggest that (1) the chronic neuropathy in the presented case is perpetuated by a lymphocyte-mediated process of delayed hypersensitivity and (2) glucocorticoids, and possibly chloroquine, act by blocking lymphocyte reactivity to effect a remission. Chloroquine has long been known to have certain 'anti-inflammatory' properties (Sams, 1967). In vitro, this drug is as effective as the glucocorticoids in inhibiting lymphocyte transformation induced by phytohaemagglutinin (Hirschhorn and Hirschhorn, 1965). It is perhaps by preventing small lymphocytes from undergoing blastic transformation in vivo that glucocorticoids, and possibly chloroquine, interrupt the proposed immunological sequence in idiopathic recurrent neuropathy and produce a clinical ro mission.

\section{SUMMARY}

An 11-year-old girl was hospitalized with a chronif recurrent polyneuropathy of three years' duration? At the time of admission she had been quadriplegic for 13 months. Three and a half months after initiation of prednisone therapy and $1 \frac{1}{2}$ month after the addition of chloroquine the patient begam to recover, ultimately improving to the point of independent ambulation. Emphasis is placed on the remarkable recovery after a prolonged period of quadriplegia and on the long latency betweeg initiation of treatment and appearance of unequivocap clinical improvement. Since recovering, the patien $\vec{D}$ has remained in remission on an alternate day pro gramme of prednisone therapy.

Certain considerations are advanced regarding the possible mechanism of disease in this case an the mode of action of the therapeutic agents in effecting a remission. It is suggested that the chronic neuropathy in the presented case may be perpenis ated by a lymphocyte-mediated process of delay d

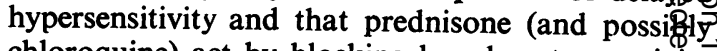
chloroquine) act by blocking lymphocyte reactifity to cause a remission.

The authors thank Dr. R. C. Griggs for performing the immunochemical studies on the cerebrospinal fluid samples and Dr. F. Q. Vroom and Dr. G. O. Walsh to performing the electrophysiological studies on this patient. Also we acknowledge the valuable assistance of the members of the Physical Therapy Department in the management and continuing care of the patiens details of whom are presented here.

\section{ADDENDUM}

The patient's improvement has been maintained an additional year (through December 1969) with some additional increase in strength, although she is stil not normal. Tendon reflexes have not improved Medications remain the same as at time of discharge

\section{REFERENCES}

Arnason, B. G., Asbury, A. K., Astrơm, K. E., and Adams, R. DO (1968). EAN as a model for idiopathic polyneuritis. Trans Amer. neurol. Ass., 93, 133-136.

Asbury, A. K., and Arnason, B. G. (1968). Experimental allergic neuritis: A radioautographic study. J. Neuropath. exp. Neurol., 27, 581-590.

Austin, J. H. (1956). Observations on the syndrome of hypertrophic. neuritis (The hypertrophic interstitial radiculo-neuropathies) N Medicine (Baltimore), 35, 187-237.

(1958). Recurrent polyneuropathies and their corticosteroid treatment with five-year observations of a placebo-controlledo case treated with corticotrophin, cortisone and prednisone $N$ Brain, 81, 157-192. 
Byers, R. K., and Taft, L. T. (1957). Chronic multiple peripheral neuropathy in childhood. Pediatrics, 20, 517-537.

DeVivo, D. C., and Engel, W. K. (1969). Alternate day glucocorticoid treatment in inflammatory myopathy. (In preparation.)

Dyck, P. J., Gutrecht, J. A., Bastron, J. A., Karnes, W. E., and Dale, A. J. D. (1968). Histologic and teased-fiber measurements of sural nerve in disorders of lower mator and primary sensory neurons. Mayo Clin. Prcc., 43, 81-123.

Engel, W. K., and Broske, M. H. (1966). Muscle biopsy as a clinical diagnostic aid, pp. 90-146 in Neurclogical Diagnostic Techniques. Edited ty W. S. Fields. Thomas: Springfield, Illinois.

Garcin, R., Lapresle, J., Farceau, M., and deR:condo, J. (1966). Etude au microscope électronique du nerf périphérique prélevé par biorsi: dans quatre cas de névritz hyrertrophique de Dejerine-Sottas. Rev. neurol., 115, 917-932.

Haymaker, W., and Kernohan, J. W. (1949). The Lardry-GuillainBarré syndrome. A clinicopathologic ro po t of fifty fatal ca'es and a critique of the literature. Mcdicine (Bcltimore), 28, 59-141.

Hinman, R. C., and Magee, K. R. (1967). Gt illain-Barré syndrome with slow progressive onset and persi.tent elevition of spinal fluid protcin. Ann. intern. Med., 67, 1007-1012.
Hirschhorn, K., and Hirschhorn, R. (1965). Role of lysosomes in the lymphocyte response. Lancet, 1, 1046-1047.

Nattrass, F. J. (1921-1922). Recurrent hypertrophic neuritis. $J$. Neurol. Psychopath., 2, 159-165.

Osuntokun, B. O., Prineas, J., and Field, E. J. (1966). Immunological study of chronic polyneuropathies of undetermined cause. J. Neurol. Neurosurg. Psychiat., 29, 456-458.

Ravn, H., and Jensen, K. (1965). Cerebrospinal fluid proteins in the Guillain-Barré syndrome. Acta path. microbiol. scand., 65 , 93-104.

Sams, W. M. (1967). Chloroquine: mechanism of action. Mayo Clin. Proc., 42, 300-309.

Thomas, P. K., and Lascelles, R. G. (1967). Hypertrophic neuropathy. Quart. J. Med., 36, 223-238.

Waksman, B. H., and Adams, R. D. (1955). Allergic neuritis: an experimental disease of rabbits induced by the injection of peripheral nervous tissue and adjuvants. J. exp. Med., 102, 213-236.

Webster, H. de F., Schröder, J. M., Asbury, A. K., and Adams, R. D. (1967). The role of Schwann cells in the formation of 'onion bulbs' found in chronic neuropathies. J. Neuropath. exp. Neurol., 26, 276-299. 